\title{
ESTUDO HISTOLÓGICO DOS PROCESSOS REGENERATIVOS DA NADADEIRA CAUDAL DO PATINGA, HÍBRIDO DE PIRAPITINGA (PIARACTUS BRACHYPOMUS) E PACU (PIARACTUS MESOPOTAMICUS)
}

\author{
Ochandio, B. S.'; Peterlini, M. F. ${ }^{2}$; Pantalhão, G. T. 2; Böckelmann, P. K. ${ }^{2}$ \& Bechara, I. J. ${ }^{\text {* }}$ \\ 1 - Departamento de Biologia do Instituto de Biociências da Universidade Estadual Paulista - \\ UNESP, Campus Rio Claro, SP. \\ 2 - Laboratório de Histofisiologia e Histopatologia Experimental em Ectotérmicos, Departamento de \\ Histologia e Embriologia do Instituto de Biologia da Universidade Estadual de Campinas - UNICAMP, \\ Campinas, SP. \\ * Contact author: ibechara@unicamp.br
}

\begin{abstract}
Ochandio, B. S.; Peterlini, M. F.; Pantalhão, G. T.; Böckelmann, P. K. \& Bechara, I. J. 2010. Histological study of the regenerative processes of the patinga tail fin, a hybrid of pirapitinga (Piaractus brachypomus) and pacu (Piaractus mesopotamicus). Braz. J. Aquat. Sci. Technol. 14(2): 63-71. ISSN 1808-7035. After partial amputation, teleostean tail fins suffer a regenerative process capable of quickly restoring its original size and shape. This process is called epimorphic regeneration and it is characterized by the following stages: the healing, based on the formation of a multistratified epidermal layer, the formation of a mass of pluripotent cells known as blastema, the differentiation of these cells, the synthesis and disposition of the extracellular matrix, the morphological growth and restoration. The most common fish used in experiments performed on fin regeneration is the zebrafish, the carp and the tilapia. So far, no studies were done on the regenerative process of the fins in Brazilian species. Thus, the objective of this work was to study the regenerative process of the tail fin of the patinga (a hybrid from the crossing of the female pirapitinga and the male pacu). For this purpose, the fish were anesthetized and had their tail fins transversally amputated $3 \mathrm{~mm}$ from the tail muscular peduncle. After 1, 2, 4, 6, 8 and 10 days of regeneration, the fins were collected, fixed and processed in order to allow the light microscope study. It was observed that the tail fins of the patinga show the same regenerative pattern already known of the zebrafish, the carp and the tilapia, which means that the regenerative process occurred in a fast and precise way, and in the same sequence of the events already known and described. Therefore, we believe that this specie is equally useful for future studies concerning, for example, biotic and abiotic effects of this process, as well as for molecular biological studies.
\end{abstract}

Keywords: teleosts, regeneration, fin.

\section{INTRODUÇÃO}

Atualmente, os estudos histológicos da nadadeira caudal dos teleósteos têm servido de modelo para estudos da regeneração tecidual, assim como fornecem informações pertinentes da expressão gênica, oferecendo bases fundamentais para estudos ao nível molecular na regeneração tecidual. Há uma cascata de genes que codificam moléculas sinalizadoras e fatores de transcrição que são induzidos após a amputação ou a injúria da nadadeira, levando à restauração das estruturas perdidas (Poss et al., 2000; Murciano et al., 2002; Nechiporuk \& Keating, 2002; Poss et al., 2003).

A despeito da importância dos estudos histológicos e moleculares para a regeneração, estes têm sido enfatizados em espécimes exóticos, como: zebrafish (Danio rerio), carpa (Cyprinus carpio) e tilápia (Tilapia melanopleura). Espécies brasileiras a cada dia tornam-se importantes para a piscicultura, quer seja pela criação em cativeiro ou pela pesca esportiva. Assim, estudos voltados para estas espécies são importantes, não somente pelo aspecto fundamental da pesquisa, mas, também, pela importância econômica. Neste sentido, o presente trabalho traz a primeira contribuição para se estudar o processo regenerativo das nadadeiras caudais do patinga, um híbrido do cruzamento da fêmea de pirapitinga, Piaractus brachypomus, e do macho do pacu, Piaractus mesopotamicus, e com esta a primeira em espécies brasileiras.

As nadadeiras dos teleósteos, quando parcialmente amputadas, passam por um processo de regeneração chamado de regeneração epimórfica, caracterizado pelas seguintes fases: cicatrização da ferida a partir da formação de uma capa epidermal apical multiestratificada, formação de uma massa de células mesenquimais multipotentes, o blastema, diferenciação dessas células, síntese e deposição de matriz extracelular, crescimento tecidual e restauração 
morfológica (Goss \& Stagg, 1957; Montes et al., 1982: Becerra et al., 1983: Santamaría \& Becerra, 1991; Géraudie \& Singer, 1992; Santamaría et al., 1992: Becerra et al., 1996; Poss et al., 2000; Murciano et al., 2002; Nechiporuk \& Keating, 2002; Santos-Ruiz et al., 2002; Akimenko et al., 2003; Poss et al., 2003; Böckelmann et al., 2009). Após a amputação, a regeneração total da nadadeira é completada aproximadamente dentro de três semanas (Becerra et al., 1996; Marí-Beffa et al., 1996; Bechara et al., 2000; Akimenko et al., 2003), processo este que se inicia quando o tecido conjuntivo presente dentro do raio é selado por um coágulo com numerosas células sanguíneas, principalmente leucócitos, e enquanto isso, células da epiderme lateral migram em direção ao plano de amputação para fechar a ferida. Um dia depois da amputação, a ferida já se encontra completamente fechada a partir da formação da capa epidermal apical que é separada do tecido conjuntivo adjacente por uma membrana basal (Böckelmann et al., 2009). Durante os dois ou três dias seguintes, o tecido conjuntivo presente entre os dois hemisegmentos (duas metades de um mesmo raio), localizados logo abaixo da capa epidermal, sofre uma desorganização e uma desdiferenciação e células indiferenciadas migram distalmente em direção à capa epidermal com a finalidade de formar o blastema, que é invadido por terminações nervosas (Goss \& Stagg, 1957; Géraudie \& Singer, 1979; Becerra et al., 1996; Poleo et al., 2001; Santos-Ruiz et al., 2002).

Durante a formação do blastema, a camada basal da epiderme, composta de células que variam da forma cubóide a cilíndrica, se dispõe de maneira adjacente ao tecido blastemal, sendo separada apenas pela presença da membrana basal (Poss et al., 2003; Böckelmann et al., 2009).

Algumas células blastemais, de morfologia homogênea, começam sua diferenciação aderindo à membrana basal da epiderme e iniciam a síntese das lepidotriquias (raios da nadadeira). Essas células diferenciadas são conhecidas como escleroblastos. Posteriormente, alguns escleroblastos migram ao longo da margem da lepidotriquia, entrando em contato com a membrana basal, habitando um espaço subepidermal, contribuindo, assim, para o crescimento do hemisegmento através da deposição de matriz na outra face da lepidotriquia (Becerra et al., 1996).

Estudos de fatores internos e externos que influenciam o processo regenerativo vêm sendo bastante descritos. Dentre os fatores internos (bióticos), a atividade da tireóide e da hipófise parece regular a velocidade de crescimento na regeneração (Grassé, 1958). Outro fator interno é a necessidade de um suprimento nervoso adequado para que ocorra a regeneração (Géraudie \& Singer, 1979). Dentre os fatores externos (abióticos), tem sido relatado que a regeneração da nadadeira é extremamente sensível à ação de agentes físicos e químicos externos. O metil-mercúrio, o óleo combustível, o TCDD (2,3,7,8-Tetraclorodibenzeno-pdioxina) e outros possíveis agentes contaminantes ambientais retardam ou até inibem a regeneração (Fingerman, 1980; Zodrow \& Tanguay, 2003), enquanto que o cádmio e o zinco interatuam antagonicamente com os anteriores, estimulando o crescimento (Weis \& Weis, 1980). Certas drogas como, por exemplo, o beta-aminopropionitrilo, a penicilamina e a aspirina inibem a síntese de colágeno e, conseqüentemente, a regeneração (Bechara et al., 2000), enquanto que o naproxeno não (Böckelmann \& Bechara, 2004, 2007).

Com o presente estudo acreditamos contribuir com dados quanto à histologia do crescimento durante o processo regenerativo dos tecidos conjuntivos que formam as nadadeiras deste peixe híbrido, oferecendo, assim, fundamentos para estudos futuros, quando poderão ser considerados fatores abióticos do ambiente, como produtos químicos, dada à importância da qualidade da água na criação e desenvolvimento da piscicultura racional.

\section{MATERIAL E MÉTODOS}

Foram utilizados, no experimento, exemplares de patinga, medindo, em média, $7 \mathrm{~cm}$ de comprimento e provenientes de um criadouro comercial. Os peixes foram mantidos no Biotério de Bioensaios em Peixes do Departamento de Histologia e Embriologia do Instituto de Biologia da UNICAMP, em Campinas, SP, em quarentena, em aquários de plástico (caixas de manutenção), com água declorada e limpa, à temperatura de $24^{\circ} \mathrm{C}$ e aeração forçada constante, dada pela utilização de bombas de aquário, e alimentados diariamente com ração apropriada para peixes.

No início do experimento, aquários de vidro com água limpa e declorada, foram montados. Os peixes foram transferidos das caixas de manutenção (aquários de plástico), onde se encontravam em quarentena, para os aquários de vidro, sendo a coleta feita ao acaso, e foram submetidos a uma fotofase de 12 horas de claro e escuro. Foram mantidos com aeração constante, com água à temperatura de $24^{\circ} \mathrm{C}$ e continuaram a receber alimentação diária. Após um período de adaptação, todos os peixes foram anestesiados com benzocaína (1:10000; SYNTH, Brasil) e tiveram suas nadadeiras caudais amputadas transversalmente (no sentido dorso-ventral) a uma distância de $3 \mathrm{~mm}$ do pedúnculo muscular da cauda, com uma navalha afiada (de acordo com Becerra et al., 1996). Após esse procedimento, os peixes voltaram para os aquários para possibilitar o estudo da regeneração. 
Para a avaliação da regeneração, os animais foram coletados e sacrificados por aprofundamento da anestesia em intervalos de 1, 2, 4, 6, 8 e 10 dias após a amputação e, em seguida, as nadadeiras em regeneração foram excisadas e fixadas em solução de Bouin por 6 horas, embebidas em parafina e cortadas a $6 \mu \mathrm{m}$. Foram utilizados três espécimes para cada intervalo de tempo. Os cortes histológicos foram corados com Hematoxilina-Eosina, Tricrômico de Masson e Picrosirius-hematoxilina (Junqueira et al., 1979) e observados em um microscópio de luz convencional e tiveram suas imagens analisadas usando um analisador de imagem (Imagem Pro-Plus, versão 4.1.12, USA).

\section{RESULTADOS}

No presente trabalho foi observado que as nadadeiras caudais do patinga apresentaram o mesmo padrão de regeneração já conhecido para o zebrafish, a carpa e a tilápia.

A reparação das nadadeiras caudais começou imediatamente após a lesão. Um dia após a amputação, as células da epiderme migraram e cobriram completamente a borda cortada na extremidade distal da nadadeira (região amputada da nadadeira) formando a chamada capa epidermal apical (Fig. 1). As células da camada basal da epiderme, por sua vez, apresenta- ram-se desenvolvidas e formando uma camada única de células cilíndricas (Fig. 1). Nesse período de regeneração, essas células da camada basal já haviam iniciado a síntese da membrana basal abaixo do novo epitélio regenerado (Fig. 1), a qual também havia sido perdida no momento da amputação da nadadeira.

No segundo dia de regeneração, o tecido conjuntivo intra-lepidotriquial havia iniciado o seu crescimento (Fig. 2). As células cilíndricas da camada basal da epiderme podem ser melhor visualizadas nesta Figura.

Com 4 dias de regeneração, a nadadeira como um todo havia crescido (Fig. 3). O blastema (uma massa de células de aspecto homogêneo) estava formado logo abaixo da epiderme em regeneração (Figs. 3 e 4). Observou-se, também, que algumas células do blastema começavam a migrar e a formar uma fileira alongada de células, uma ao lado da outra, imediatamente abaixo da epiderme, em íntima associação com a membrana basal, em ambos os lados da nadadeira (Figs. 3 e 5). Estas células, chamadas de escleroblastos, iniciaram a síntese e a deposição da matriz extracelular da lepidotriquia na região voltada para a membrana basal e, portanto, entre a fileira de escleroblastos e a membrana basal da epiderme (Fig. $5)$.

No sexto dia de regeneração, pôde-se observar que a nadadeira como um todo havia crescido ainda

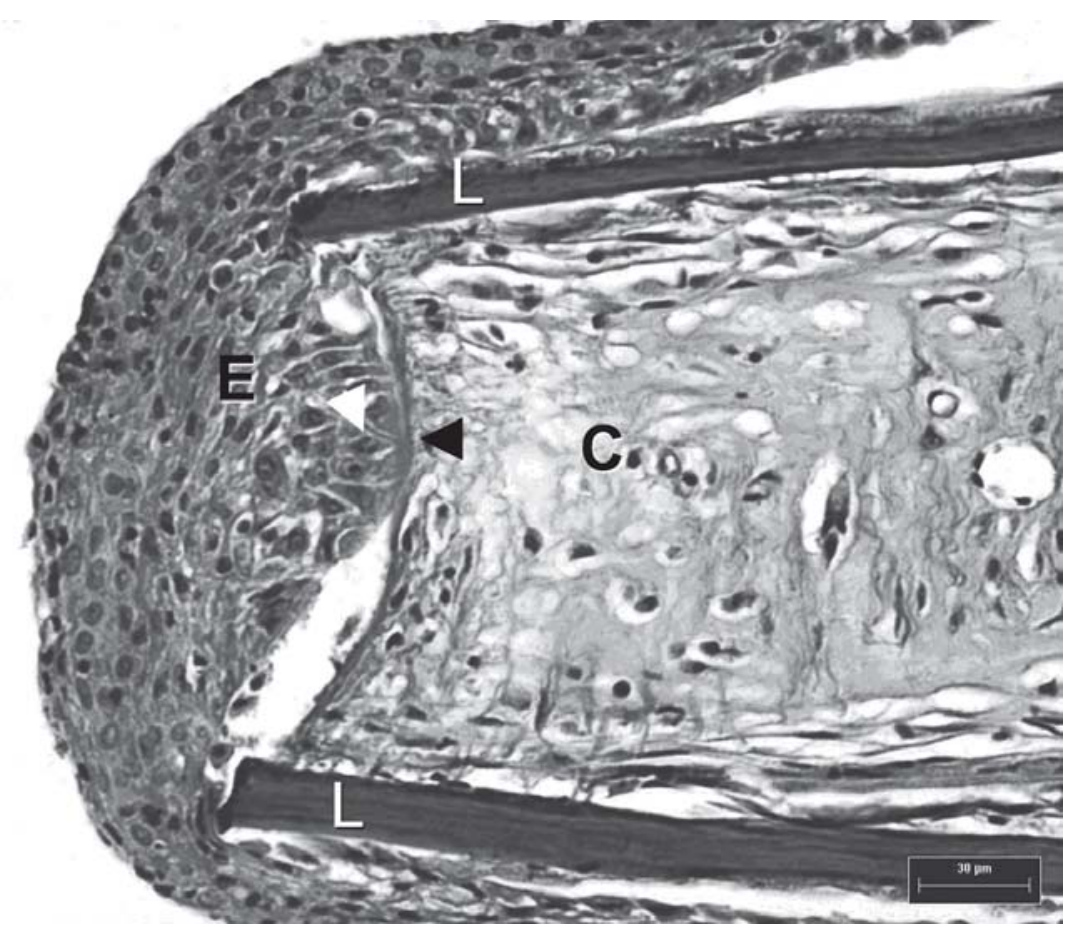

Figura 1 - Fotomicrografia de um corte longitudinal da região distal de uma nadadeira caudal do patinga com 1 dia de regeneração. A epiderme $(E)$ cobriu a extremidade da nadadeira cortada, fechando a ferida. $L$ = lepidotriquia velha (não sofreu regeneração). Seta preta = local de amputação. $\mathrm{C}=$ tecido conjuntivo não regenerado. Cabeça de seta branca = células cilíndricas da camada basal da epiderme. Cabeça de seta preta = membrana basal do epitélio. Picrosirius-hematoxilina. Barra: $30 v \mathrm{~m}$. 


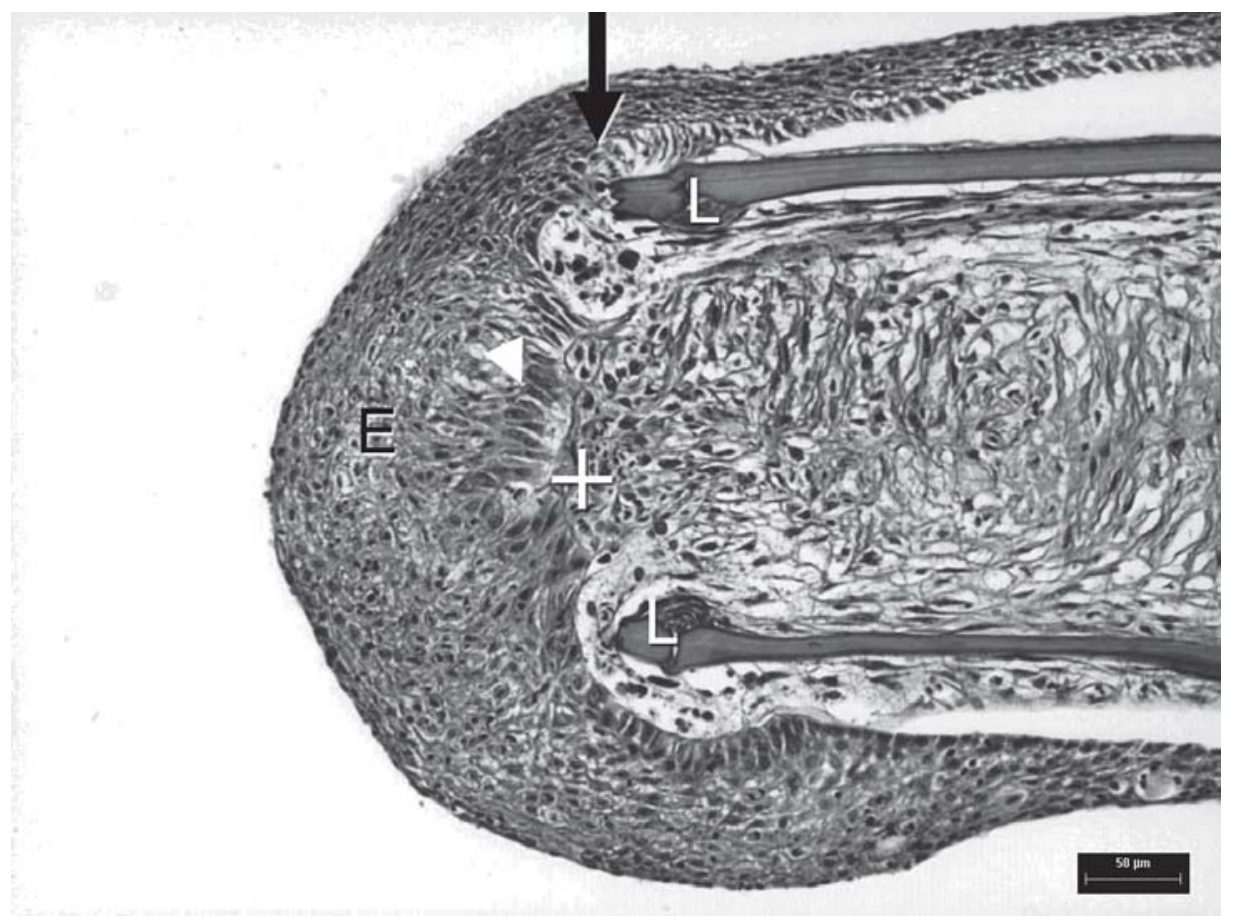

Figura 2 - Fotomicrografia de um corte longitudinal da região distal de uma nadadeira caudal com 2 dias de regeneração. O tecido conjuntivo começa a regenerar $(+)$. $E=$ epiderme em regeneração. $L=$ lepidotriquia velha (não sofreu regeneração). Seta preta $=$ local de amputação. $\mathrm{C}$ = tecido conjuntivo não regenerado. Cabeça de seta branca = células cilíndricas da camada basal da epiderme. Picrosirius-hematoxilina. Barra: 50um.

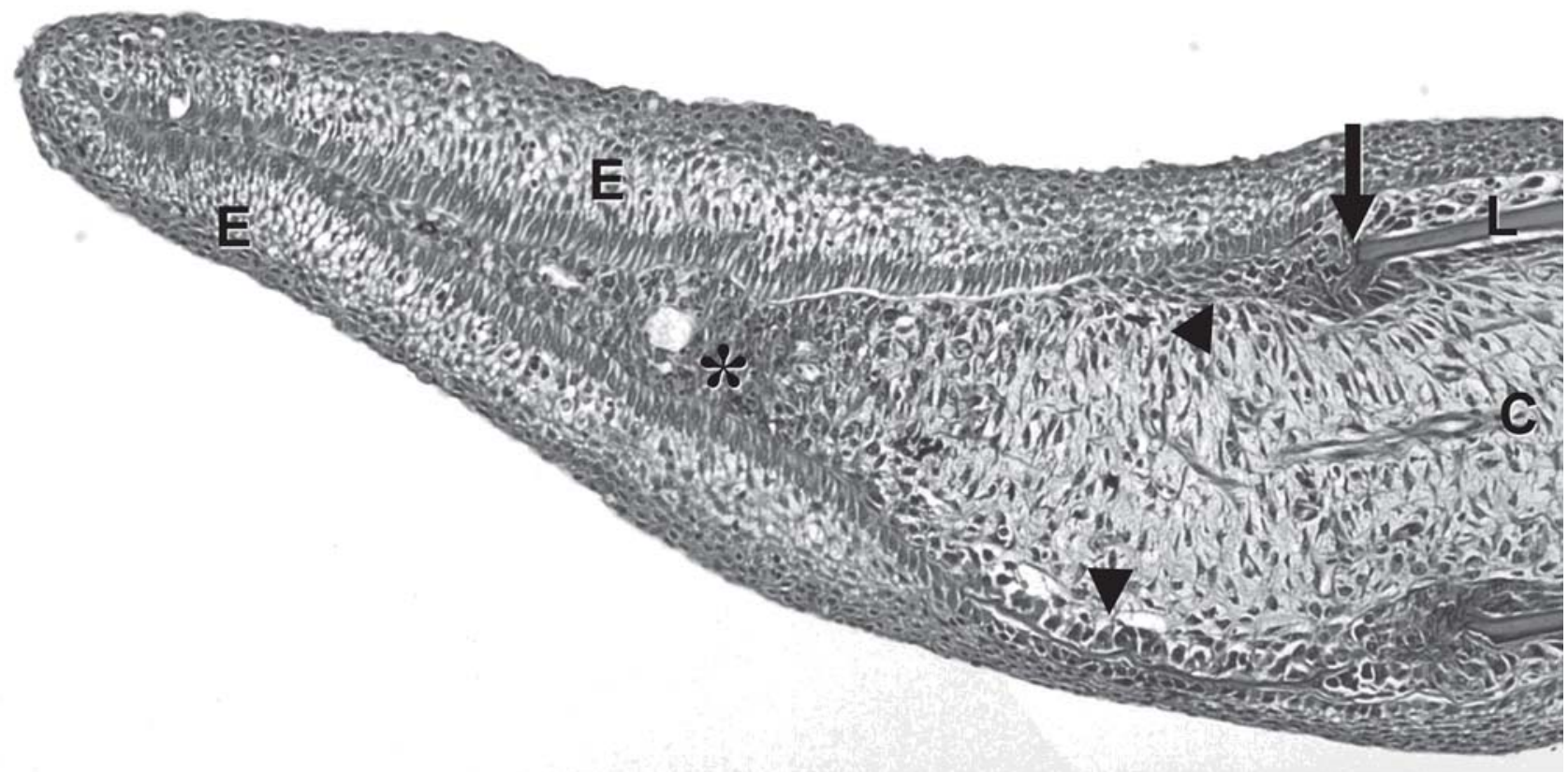

Figura 3 - Imagem obtida pela união de duas fotomicrografias da nadadeira caudal com 4 dias de regeneração. $\mathrm{E}=$ epiderme em regeneração. $L$ = lepidotriquia velha (não sofreu regeneração). Seta preta = local de amputação. $C=$ tecido conjuntivo não regenerado. $\mathrm{CR}=$ tecido conjuntivo em regeneração. Asterisco = blastema. Cabeças de setas pretas = escleroblastos (células produtoras das lepidotriquias). Picrosirius-hematoxilina.

mais (Fig. 6), quando comparada com a nadadeira com 4 dias de regeneração (Fig. 3). Os escleroblastos começaram a migrar para o outro lado do hemisegmento da lepidotriquia em regeneração e se interpuseram entre a epiderme e o hemisegmento, mantendo a disposi- ção de uma camada única de células envolvendo, agora, os dois lados do hemisegmento lepidotriquial e passaram a secretar matriz extracelular para o lado voltado para o hemisegmento (Fig. 7). 


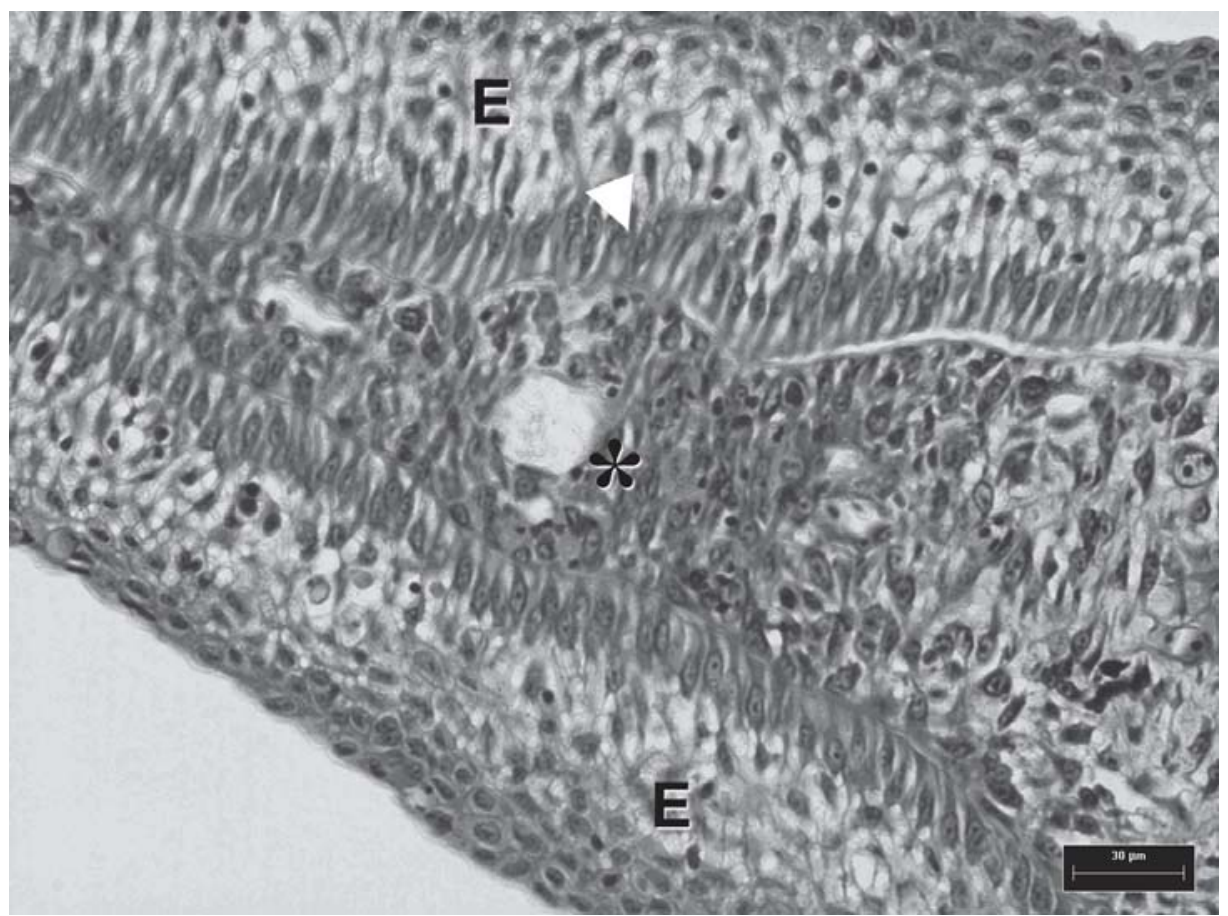

Figura 4: Mesma fotomicrografia da Figura 3, vista com aumento maior. E = epiderme em regeneração. Asterisco = blastema. Cabeça de seta branca $=$ células cilíndricas da camada basal da epiderme. Picrosirius-hematoxilina. Barra: $30 \mu m$.

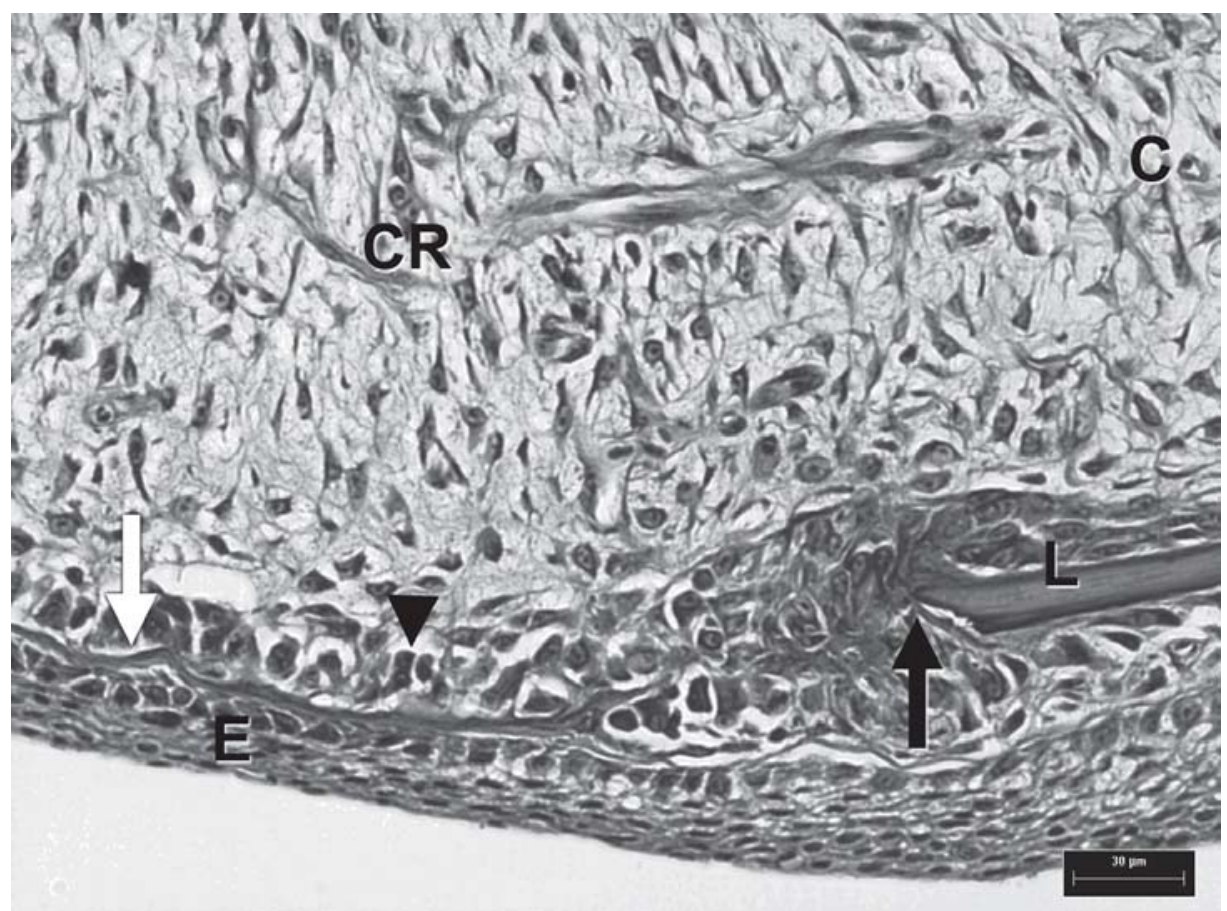

Figura 5: Fotomicrografia de um corte longitudinal da região distal de uma nadadeira caudal com 4 dias de regeneração. Em foco, o ponto de amputação da nadadeira. $E$ = epiderme em regeneração. $L=$ lepidotriquia velha (não sofreu regeneração). Seta preta $=$ local de amputação. $\mathrm{C}$ = tecido conjuntivo não regenerado. $\mathrm{CR}$ = tecido conjuntivo em regeneração. Seta branca = lepidotriquia em regeneração. Cabeça de seta preta $=$ escleroblastos. Tricrômico de Masson. Barra: $30 \mu \mathrm{m}$.

Nos dias 8 e 10 de regeneração, a lepidotriquia alongou-se devido a um crescimento próximo-distal, tornando-se cada vez maior em comprimento. Em espessura, o crescimento ocorreu pela ação dos escleroblastos que depositaram matriz extracelular, sendo responsáveis pelo espessamento do hemisegmento através do crescimento aposicional (as camadas lepidotriquiais centrais são mais velhas do que as mais externas) (Fig. 8). 


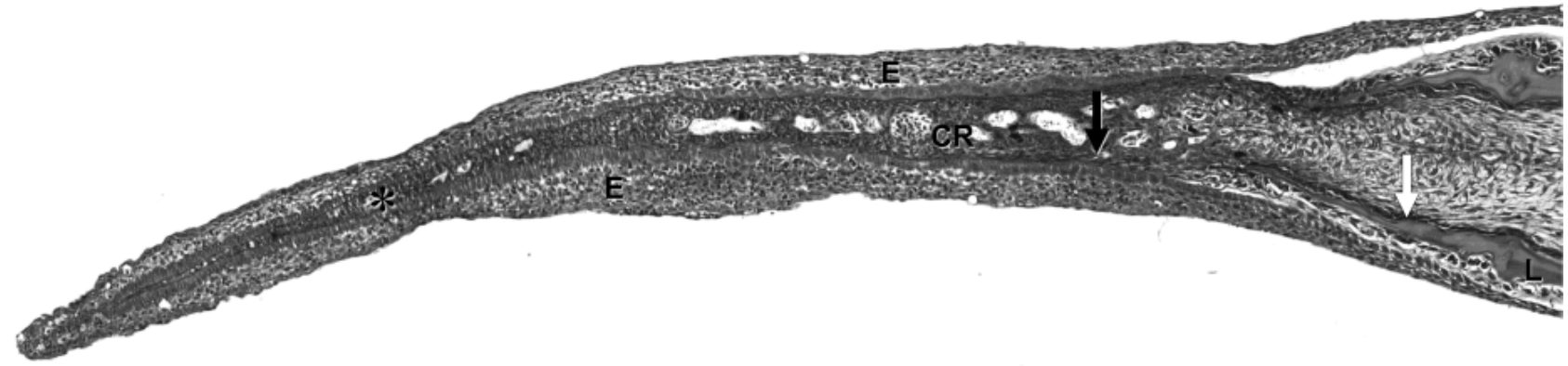

Figura 6: Imagem obtida pela união de três fotomicrografias da nadadeira caudal com 6 dias de regeneração. $E=$ epiderme em regeneração. $L=$ lepidotriquia velha (não sofreu regeneração). Seta preta = local de amputação. $C R=$ tecido conjuntivo em regeneração. Seta branca = lepidotriquia em regeneração. Asterisco = blastema. Picrosirius-hematoxilina.

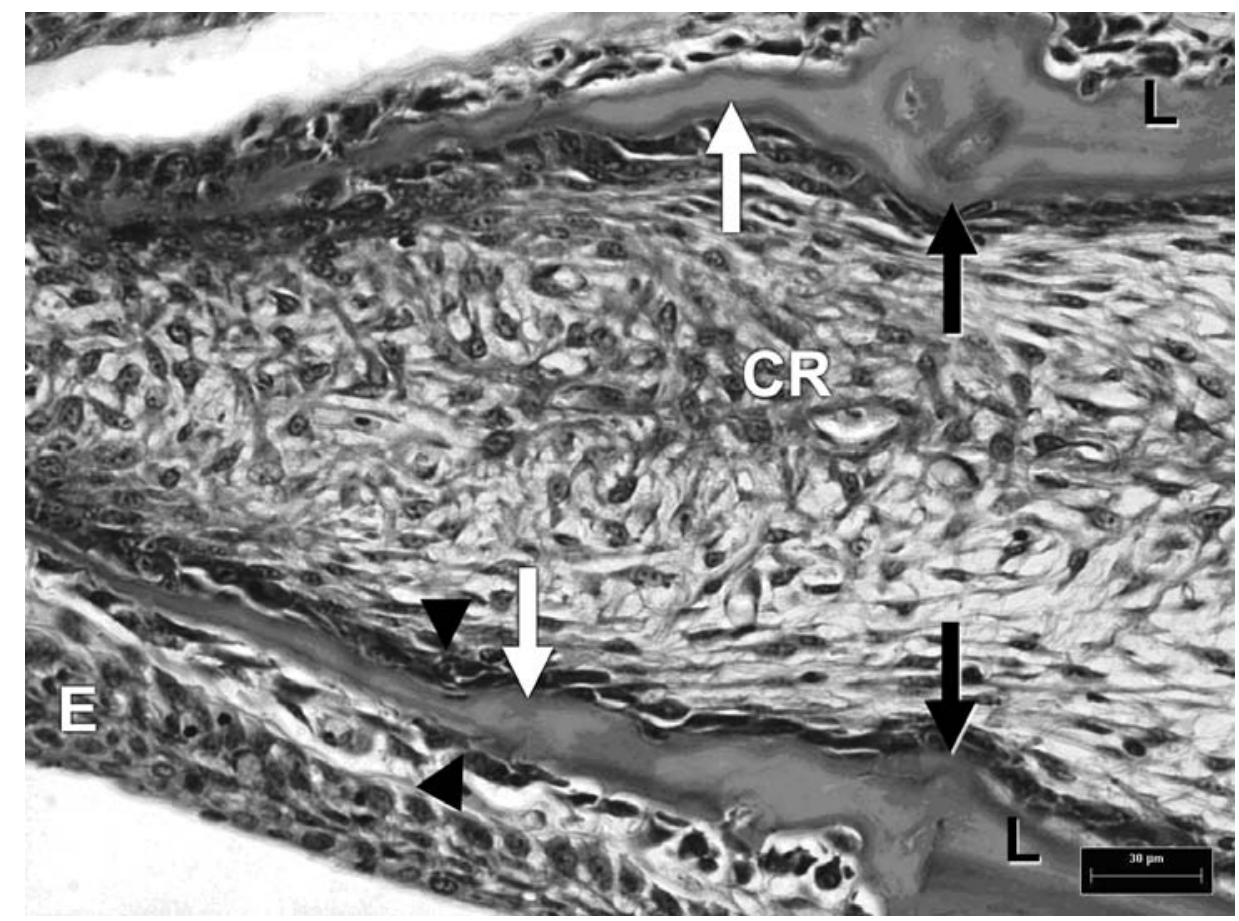

Figura 7: Mesma fotomicrografia da Figura 6, vista com aumento maior. $E$ = epiderme em regeneração. $L=$ lepidotriquia velha (não sofreu regeneração). Setas pretas $=$ local de amputação. $\mathrm{C}=$ tecido conjuntivo não regenerado. $\mathrm{CR}=$ tecido conjuntivo em regeneração. Setas brancas = lepidotriquia em regeneração. Cabeças de setas pretas = escleroblastos em ambos os lados do hemisegmento lepidotriquial. Picrosirius-hematoxilina. Barra: $30 \mu \mathrm{m}$.

\section{DISCUSSÃO}

Alguns vertebrados inferiores, tais como anfíbios urodelos e peixes teleósteos, possuem uma alta habilidade de regeneração em uma variedade de tecidos e órgãos, enquanto os mamíferos têm uma capacidade regenerativa limitada. Esta diferença é vista como sendo um processo onde os animais, ao longo da evolução, foram perdendo gradualmente a sua habilidade em regenerar partes perdidas ou danificadas. Esta mudança na capacidade regenerativa durante o curso da evolução está intimamente ligada com a conservação de muitos genes e a expressão e função desses entre as espécies de vertebrados (Nakatani et al., 2007).
A nadadeira caudal dos peixes teleósteos representa um modelo simples de sistema em regeneração que pode ser útil para ilustrar os princípios biológicos ao nível epimórfico envolvidos na regeneração e na expressão gênica. Por sua vez, a manipulação histológica permite o acompanhamento e a observação microscópica do crescimento e da proliferação em organismos multicelulares (Becerra et al., 1996; Bechara et al., 2000; Böckelmann \& Bechara, 2004, 2007; Böckelmann et al., 2009).

Estudos moleculares da regeneração das nadadeiras em zebrafish têm identificado vários genes envolvidos no processo regenerativo. Um dos primeiros marcadores moleculares que aparece logo nas primeiras horas após a amputação, e que é mantido durante 


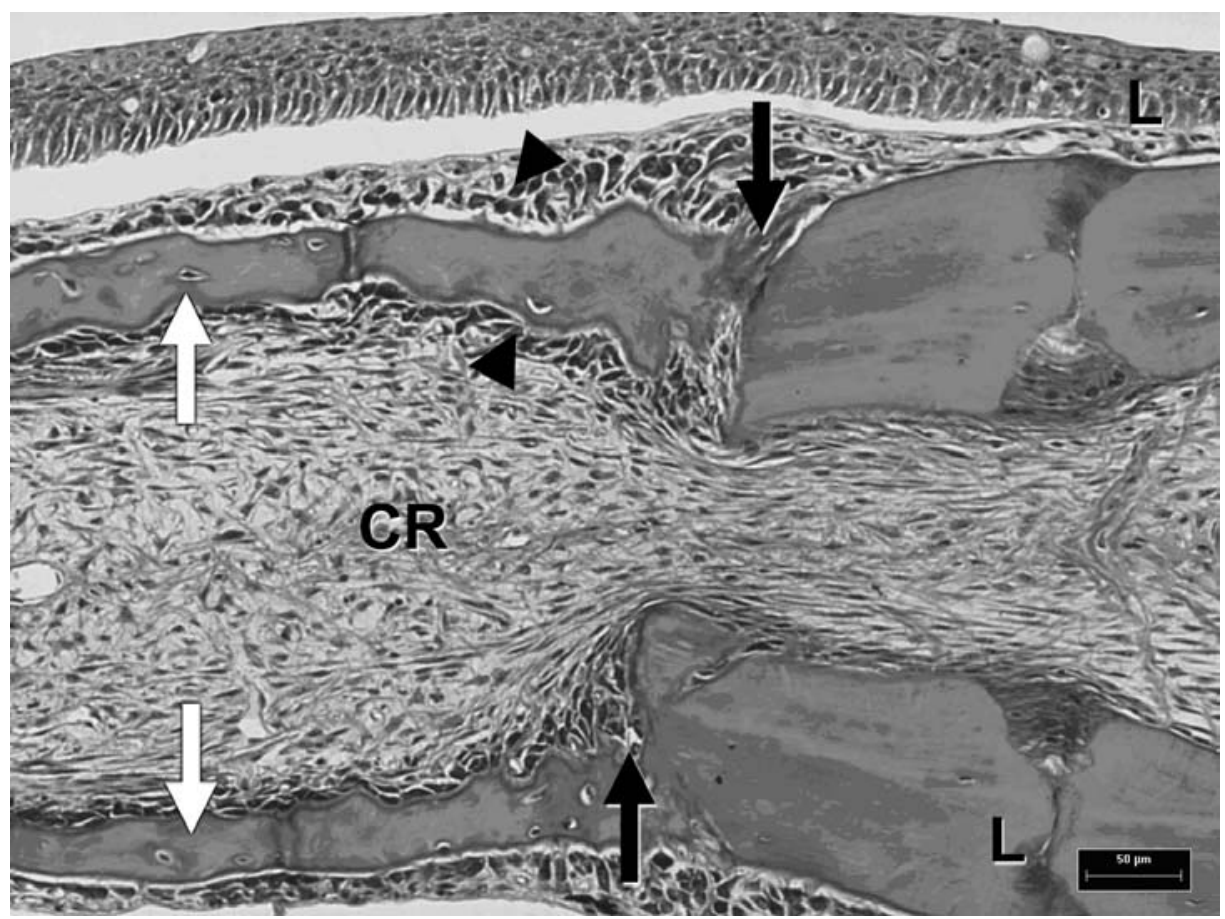

Figura 8: Fotomicrografia de um corte longitudinal da região distal de uma nadadeira caudal com 8 dias de regeneração. $\mathrm{E}=$ epiderme em regeneração. $\mathrm{L}$ = lepidotriquia velha (não sofreu regeneração). Setas pretas = local de amputação. $C=$ tecido conjuntivo não regenerado. $\mathrm{CR}$ = tecido conjuntivo em regeneração. Setas brancas = lepidotriquia em regeneração. Cabeças de setas pretas = escleroblastos em ambos os lados do hemisegmento lepidotriquial. Tricrômico de Masson. Barra: $50 \mu \mathrm{m}$.

todo o processo, é a expressão da $\beta$-catenina nas células epidermais que estão cobrindo o local da amputação, formando a capa epidermal apical (Poss et al., 2000). Pressupõe-se que o aumento da expressão desse gene está relacionado com a função em manter a interação célula-célula para facilitar a migração das células epidermais, e para realizar a manutenção da epiderme (Poss et al., 2003). Suspeita-se que a capa epidermal madura seja a fonte de fatores de crescimento que estimulam a formação e a manutenção da função do blastema em regeneração, uma vez que na ausência da capa epidermal não há regeneração (Goss, 1991). Um dos fatores que pode estimular a formação do blastema é o gene Wnt5, que é detectado na capa epidermal, principalmente na camada basal da epiderme, nos últimos estágios da regeneração (Poss et al., 2000).

Akimenko et al. (1995) estudaram a expressão de quatro genes homeobox da família $m s x$ : $m s x A$, $m s x B, m s x C$ e $m s x D$, durante a regeneração da nadadeira e observaram que a expressão desses genes é fortemente reinduzida durante o processo regenerativo. O nível de expressão desses genes aumenta muito durante a formação do blastema e, em seguida, cai progressivamente e desaparece quando a nadadeira volta ao seu tamanho normal. Esses autores observaram, também, que as células do blastema expressam msxB e $m s x C$, e que as células da epiderme, que reveste a nadadeira, expressam $m s x A$ e $m s x D$. No entanto, não houve expressão detectável desses quatro genes na região da nadadeira que já sofreu diferenciação.

Outro fator de crescimento expresso na capa epidermal é o gene shh, que é responsável pela diferenciação, alinhamento e proliferação dos escleroblastos (Poss et al., 2003).

Verifica-se, assim, a importância da regeneração das nadadeiras para os estudos de biologia molecular. Estudos ambientais têm revelado, também, a importância da regeneração das nadadeiras como um modelo para se determinar os efeitos de contaminantes ambientais na água, tais como, metais pesados e agrotóxicos, bem como, também, fatores físicos como a luz e a temperatura (Fingerman, 1980; Weis \& Weis, 1980; Johnson \& Weston, 1995; Nechiporuk \& Keating, 2002; Zodrow \& Tanguay, 2003; Whitehead et al, 2005), ou, até mesmo, para testes de contaminantes em laboratório como, por exemplo, a utilização de drogas antiinflamatórias para a observação de seus efeitos no processo regenerativo (Bechara et al., 2000; Böckelmann \& Bechara, 2004, 2007).

Em nossos estudos histológicos anteriores, utilizando-se a carpa e a tilápia como modelos biológicos observamos que, durante o processo regenerativo, logo nas primeiras horas após a amputação, células da epiderme lateral, que não sofreram danos, migram para a região amputada da nadadeira com o objetivo de cobrir rapidamente a ferida. Em seguida, células da camada basal da epiderme passaram por um dimorfismo, 
indo da forma cúbica para a cilíndrica, quando se observa a produção da membrana basal. No quarto dia da regeneração, observou-se a formação de uma massa proliferativa de células progenitoras pluripotentes denominada blastema, e, a partir daí, a reconstituição do complexo tecido envolvendo múltiplos tipos celulares como, por exemplo, a reconstituição das lepidotriquias, do tecido conjuntivo, entre outros (Becerra et al., 1996; Bechara et al., 2000; Bechara et al., 2003; Böckelmann \& Bechara, 2004, 2007; Böckelmann et al., 2009). Isto foi, também, observado em zebrafish (Marí-Beffa et al., 1989; Santamaría \& Becerra, 1991; Géraudie \& Singer, 1992; Marí-Beffa et al., 1996; Poleo et al., 2001; Santos-Ruiz et al., 2002; Akimenko et al., 2003; Poss et al., 2003; Nakatani et al., 2007).

Neste trabalho, os estudos sobre a regeneração das nadadeiras caudais em patinga foram conduzidos do primeiro até o décimo dia da regeneração. Assim, verificou-se a ocorrência de todos os eventos já relatados para a regeneração em outras espécies de teleósteos, ou seja, no primeiro dia após a amputação houve a cicatrização do local ferido e a formação da capa epidermal apical. No segundo dia o tecido conjuntivo já havia iniciado o seu crescimento. No quarto dia houve a formação do blastema e já era possível observar as lepidotriquias em formação. No sexto dia de regeneração as lepidotriquias estavam maiores em comprimento e largura e, daí por diante, as nadadeiras continuaram o seu crescimento.

Verificamos, portanto, que, à semelhança de outras espécies de teleósteos, o patinga apresentou também, nas condições de estudo, capacidade regenerativa epimórfica bastante rápida e precisa e na mesma seqüência de eventos já conhecida e descrita na literatura. Assim, acreditamos ter trazido uma contribuição para o estudo deste híbrido nacional que se apresenta igualmente útil para estudos futuros envolvendo, por exemplo, efeitos bióticos e abióticos sobre este processo, bem como para estudos de biologia molecular e da expressão gênica.

\section{AGRADECIMENTOS}

Os autores agradecem ao pesqueiro "Recanto dos Peixes" pelo fornecimento dos peixes. Agradecem, também, à Sra. Cleusa de Oliveira Franco pela assistência técnica e ao Sr. Baltazar Pereira de Paula pela assistência técnica com os peixes.

\section{REFERÊNCIAS}

Akimenko, M.; Johnson, S.; Westerfield, M. \& Ekker, M. 1995. Differential induction of four msx homeobox genes during fin development and regeneration in zebrafish. Development. 121: 347-357.

Akimenko, M.; Marí-Beffa, M.; Becerra, J. \& Géraudie, J. 2003. Old questions, new tools, and some answers to the mystery of fin regeneration. Developmental Dynamics. 226: 190-201.

Becerra, J.; Montes, G.S.; Bexiga, S.R.R. \& Junqueira, L.C.U. 1983. Structure of the tail fin in teleosts. Cell Tissue Res. 230: 127-137.

Becerra, J.; Junqueira, L.C.U.; Bechara, I.J. \& Montes, G.S. 1996. Regeneration of fin rays in teleosts: A histochemical, radioautographic, and ultrastructural study. Arch. Histol. Cytol. 59, no 1: 15-35.

Bechara, I.J.; Joazeiro, P.P.; Marí-Beffa, M.; Becerra, J. \& Montes, G.S. 2000. Collagen-affecting drugs impair regeneration of teleost tail fins. Journal of Submicroscopic Cytology and Pathology. 32 (2): 273-280.

Bechara, I. J.; Böckelmann, P. K.; Montes, G. S. \& Cruz-Höfling, M. A. 2003. Inhibition of caudal fin actinotrichia regeneration by acetylsalicylic acid (aspirin) in teleosts. Brazilian Journal of Morphological Sciences, 20 (2): 67-74.

Böckelmann, P.K. \& Bechara, I.J. 2004. Effect of naproxen on tail fin regeneration in teleost. $\mathrm{J}$. Submicrosc. Cytol. Pathol. 36: 55-64.

Böckelmann, P.K. \& Bechara, I.J. 2007. Histochemical and ultrastructural study of the action of naproxen on tail fin regeneration of teleost. Brazilian Journal of Morphological Sciences. 24 (1): 17-24.

Böckelmann, P. K.; Ochandio, B. S. \& Bechara, I. J. 2009. Histological study of the dynamics in the epidermis regeneration of the carp tail fin (Cyprinus carpio). Brazilian Journal of Biology (aceito para publicação).

Fingerman, S.W. 1980. Differences in the effect of fuel oil, and oil dispersant, and three polichiorinated biphenyls on fin regeneration in the gulf coast killifish, Fundulus grandis. Bull. Environ. Contam. Toxicol. 23: 230-240.

Géraudie, J. \& Singer, M. 1979. Nerve dependent macromolecular synthesis in the pectoral fin regenerate of the fish Fundulus. J. Exp. Zool. 208: 281-286.

Géraudie, J. \& Singer, M. 1992. The fish fin regeneration. Monogr. Dev. Bio. 23: 62-72.

Goss, R.J. \& Stagg, M.W. 1957. The regeneration of fins and fin rays in Fundulus heteroclitus. J. Exp. Zool. 136: 487-508.

Goss, R. 1991. The natural history (and mystery) of regeneration. In: Dinsmore CE editor. A history of regeneration research. Millestones in the evolution of a science. Cambridge: Cambridge University Press. 7-23. 
Grassé, P. 1958. Rayons des nageoires. In: Traité de Zoologie. Paris, Masson. V. 13 tl p. 731-747.

Johnson, S. \& Weston, J. 1995. Temperature-sensitive mutations that cause stage-specific defects in zebrafish fin regeneration. Genetics. 141(4): 15831595.

Junqueira L.C.U.; Bignolas, G. \& Brentani, R.R. 1979. Picrosirius staining plus polarization microscopy, a specific method for collagen detection in tissue sections. Histochem J. 11: 447-455.

Marí-Beffa, M.; Carmona, M. \& Becerra, J. 1989. Elastoidin turnover during tail fin regeneration in teleosts. A morphometric and radioautographic study. Anat. Embryol. 180: 465-470.

Marí-Beffa, M.; Mateos, I.; Palmqvist, P. \& Becerra, J. 1996. Cell to cell interactions during teleosts fin regeneration. Int. J. Dev. Biol., Suppl.1: 179s-180s.

Montes, G.S.; Becerra, J.; Toledo, O.; Gordilho, M. \& Junqueira, L.C.U. 1982. Fine structure and histochemistry of the tail fin ray in teleosts. Histochemistry. 75: 363-376.

Murciano, C.; Fernández, T.D.; Durán, I.; Maseada, D.; Ruiz, J.; Becerra, J.; Akimenko, M. \& Marí-Beffa, M. 2002. Ray-interray interactions during fin regeneration of Danio rerio. Dev. Biol. 252, 214-224.

Nakatani, Y.; Kawakami, A. \& Kudo, A. 2007. Cellular and molecular processes of regeneration, with special emphasis on fish fins. Develop. Growth Differ. 49: 145-154.

Nechiporuk, A. \& Keating, M.T. 2002. A proliferation gradient between proximal and msxb-expressing distal blastema directs zebrafish fin regeneration. Development. 129: 2607-2617.

Poleo, G.; Brown, C.; Laforest, L. \& Akimenko, M. 2001. Cell proliferation and movement during early fin regeneration in zebrafish. Dev. Dyn. 221: 380-390.

Poss, K.D.; Shen, J. \& Keating, M.T. 2000. Induction of lef 1 during zebrafish fin regeneration. Dev. Dyn. 219: 282-286.

Poss, K.D.; Keating, M.T. \& Nechiporuk, A. 2003. Tales of Regeneration in Zebrafish. Developmental Dynamics. 226: 202-210.

Santamaria, J.A. \& Becerra, J. 1991. Tail fin regeneration in teleosts: cell-extracellular matrix interaction in blastemal differentiation. J. Anat. 176: 9-21.

Santamaría, J.A.; Marí-Beffa, M. \& Becerra, J. 1992. Interactions of the lepidotrichial matrix components during tail fin regeneration in teleosts. Differentiation. 49: 143-150.

Santos-Ruiz, L.; Santamaría, J.A.; Ruiz-Sânchez, J. \& Becerra, J. 2002. Cell proliferation during blastema formation in the regenerating teleost fin. Developmental Dynamics. 223: 262-272.

Weis, P. \& Weis, J. 1980. Effect of zinc on fin regeneration in the mummichog, Fundulus heteroclitus, and its interaction with methylmercury. Fish Bull. 78: 163-166.

Whitehead, G.G.; Makino, S.; Lien, C. \& Keating, M.T. 2005. fgf20 Is essential for initiating zebrafish fin regeneration. Science. 310: 1957-1960.

Zodrow, J. \& Tanguay, R. 2003. 2, 3, 7, 8Tetrachlorodibenzo- $p$-dioxin inhibits zebrafish caudal fin regeneration. Toxicological Sciences. 76: 151161.
Submetido: Maio/2009 Revisado: Janeiro/2010 Aceito: Fevereiro/2010 